\title{
Humanizing Work and Work Environment: A challenge for developing countries
}

During the period from 1750 to 1850 , numerous changes occurred in different industrial sectors in Europe, starting from manufacturing to transportation, for the betterment of productivity and human wellbeing. This period is designated as the period of industrial revolution. In this period, the concept of interventions revolved around the ways in which only productivity can be enhanced. Therefore application of interventions was not destined to reduce the sufferings of workers. In those days, less importance was given on human health and safety.

Towards the end of $19^{\text {th }}$ century, the wave of industrial revolution touched India. A large number of industries were developed by colonial British government with imported machineries from Europe and without humanizing the work and work environment. Workers' awareness of health and safety was not there. In fact, demand for good working environment was absent in various parts of the globe. This age may be depicted as the Dark Age for industrial workers. Unfortunately, this age is persisting till now in different developing countries.

Application of interventions in developing countries totally depends on the sustainability of these interventions in developing societies. Sometimes, we misunderstand this truth and try to compare with developed countries.

I am still remembering the first day of my ergonomics class and the very first lecture of my teacher Prof. Rabindra Nath Sen. He was describing the application of ergonomics in developing countries. In those times we were very much enthusiastic to learn about the enhancement of productivity in unorganized sectors by the application of modern technological interventions. With a shallow knowledge about unorganized sectors, that day, it was very easy for us to think and give solutions on productivity related problems. I remembered that we vehemently opposed the concept of our teacher that low cost improvement through low cost interventions in unorganized sector was the best solution for productivity improvement. We were utterly wrong that day. It is very easy to think about the development of humanizing work and work environment in developed countries but the economic differences make it very hard to think in developing countries where human health and safety is less important to think about.

We can define a developing country as the country that does not allow its citizens to "enjoy a free and healthy life in a safe environment". This is indeed a hard reality. In developing countries, man moves mountains, literally to speak, as he performs stupendous load handling either overhead or involving other body parts. Moreover the severity of load carriage is hastened manifold as the work environment is invariably hazardous, where the workers are exposed for more than ten hours a day on a regular basis.

Our world is segregated into a group of countries with modern industries, stable political and economic situations, high levels of awareness about human health, and another segment of countries with immense adversities like abject poverty, political turmoil and economic instability. But gradually, this situation is changing and workers are now demanding for healthy and safe working environment even in the less developed countries. There is another demand from other side, the demand for better productivity or more productivity. This demand, in turn, ushers an even stressful condition in industrially developing countries. This is because although enhancement in productivity is given prime importance but it is not accompanied by improvements or modifications in work pattern and environment.

Demand for health and safety is a common and genuine demand both from developing and developed countries. A significant difference is observed between 
developed and developing countries on interest for researches in occupational health. It may be due to the lack of basic data in developing countries. In India, statistics on occupational diseases and injuries is not maintained regularly. A similar picture has emerged from other developing countries as well. Minimum availability of funding for occupational health research may be another underneath reason for this condition. By sensing the urgency and immediate necessity of the hour, this special issue of WORK is dedicated to researchers on humanizing work and work environment.

In 2009, the Department of Physiology, University of Calcutta had organized an International Conference on Ergonomics. The conference was supported by International Ergonomics Association (IEA). The three day long conference was spread over five different locations within the heritage campus of University of Calcutta.

About 150 papers were presented over seven scientific sessions on Ergonomics in Occupational Health and Safety; Ergonomics in Organized and Unorganized Sectors; Ergonomics in Intervention and Design; Ergonomics in Agriculture; Ergonomics in Sports, Work and Exercise Physiology; Disability and Design Ergonomics and Ergonomics for Women at Work by registered participants from different regions of India including speakers from 5 different countries like the United States of America, Canada, Australia, Japan and Taiwan.

Among these papers, seven on different dimensions of this theme are included in this special issue. Except for one, all the papers are from India. Readers will get a distinct idea of work and working conditions in this developing country. Specific interventions were suggested in some of the papers and their efficacies were judged.

Among these seven papers, three papers are on the development of interventions, three papers on the assessment of physical and mental health and one paper is on the development of methodology for the assessment of health hazards. These diversified articles will definitely create interest among the readers and make them inquisitive to learn more about occupational health and its protective measures.

Now, we will make a quick journey through the accepted seven papers:

In India since the last few years, the number of women involved in different occupations is increasing manifold. Since the work process and methods are conducive for male working population who had been the dominant work group for years, the women are confronting a host of occupational problems. One of the papers emphasizes some of the design development possibilities for women workers who are engaged in local fruit processing units in various parts of North East India. Studies have been conducted with the intent to increase productivity through design development to suit the working conditions and physical compatibility of women workers.

Another interesting study was done on the fabric dyers where conventional age old methods of dyeing yarns and fabrics involved usage of poorly designed tubs. Consequently the workers had to adopt awkward postures for prolonged periods to work in those tubs. Under these circumstances the tubs were redesigned which subsequently lessened the discomfort from severe to moderate level and also resulted in a rise of productivity.

Another study involved works on goldsmiths where muscle fatigue and respiratory stress were assessed. The reduced lung volumes and peak expiratory flow rates of goldsmiths resulted from heavy pressure by using blow pipe leading to the fatigue of facial muscles. To overcome the problem, depending on the preference of goldsmiths, effective ergonomic intervention was implemented.

In another paper, the methodology for assessment of musculoskeletal disorders of the jewellery manufacturing workers was depicted.

The study on pile drivers was performed in another interesting paper, with PATH work-sampling observation method to identify the physical or ergonomic exposures that contribute to the onset of musculoskeletal injuries.

Since India is such a country where even today agriculture is one of the most predominant occupations, many research works have been done in this arena to improve productivity. The paper discussed here tries to explore the highly strenuous and time consuming process of rice pounding using indigenous traditional tools and techniques. The study is important in the sense that many indigenous food items such as flaked rice, roasted powdered rice, plain powdered rice etc are consumed regularly by a huge Indian population.

Again if agriculture occupies the first position in terms of the occupation of Indians, then the construction sector is also a booming field in recent years with the stupendous expansion of real estate. Therefore not only the construction site labourers but also the managers at the sites are the worst sufferers. Since supervision is a very tedious job, the managers have no respite; in fact, their overall health and well being are terribly hampered. Moreover musculoskeletal disor- 
ders involving low back pain have become a part of their occupation.

Therefore the special issue is an ensemble of diverse collection of papers which will serve as a treasure trove for aspiring researchers throughout the world, who have the thrust for "Humanizing Work and Work Environment".
Guest Editor

Somnath Gangopadhyay

Associate Professor

Occupational Ergonomics Laboratory

Department of Physiology

University of Calcutta

92 APC Road

Calcutta 700009, India

E-mail: ganguly1961@yahoo.com 